\title{
Three Principles of Akkie Management
}

\author{
Manuel Arulmani, Victor Ranjitham Hema Latha \\ BSNL Government of India, Madurai, India. \\ Email: m.arulmani58@gmail.com,vrhemalatha58@gmail.com
}

Received June $18^{\text {th }}, 2013$; revised July $16^{\text {th }}, 2013$; accepted July $25^{\text {th }}, 2013$

Copyright (C) 2013 Manuel Arulmani, Victor Ranjitham Hema Latha. This is an open access article distributed under the Creative Commons Attribution License, which permits unrestricted use, distribution, and reproduction in any medium, provided the original work is properly cited.

\begin{abstract}
The role of management is considered essential for setting the effective goal, realization of the goal and growth of any organization. The objective of management is to weed out the weakness and build up strongness for overall success of any organization and ultimately creating positive environment and promote the peace among people of the global soil. Management shall alternatively mean cherish, create a conducive environment. The principles of management shall be considered as the tools of human having existed since origin of human. The management tools are required not only for human but also every life organism for successful sustainability of life (Ref. [1]). In Modern Management there are thousands of theories and principles exist as a regulative means. Every organization has its own strategy and is constantly modifying the strategy to evolve new principles for conducting new business and to create new conducive environment. But all the organizations are not successful. What is the reason for the failure? The main reason for failure of objective shall be considered as "deviation to prehistoric standard Akkie principles". Hence "TRANSFORMATION" is required in all types of business in all organizations. Transformation shall mean reset to Akkie principles. Authors focuse that Akkie principles shall be considered as the most fundamental principles (Ref. [2]). It is hypothesized that the prehistorical population has already lived in MARS planet. They shall be considered as Akkie population. The Akkie population shall also be considered as black population. The principles of modern management shall be transformed from the fundamental principles of prehistoric Akkie population called as Akkie principles, Akkie management (Ref. [2-4]). The human population lived in MARS planet in prehistoric time shall be called as SUPER MANAGERS with super wisdom. They were considered as great astronomers and experts in management of various planets and in the space in overcoming the prehistoric severe climate conditions occurred due to misalignment of planets. They had only three fundamental principles of management called AKKIE PRINCIPLES or AKKIE CODE. The Akkie principles shall be considered as most effective in achieving the desired goals, objectives in space management. Akkie code shall be considered as a prehistoric high-level language in CODE FORM (Ref. [1-5]). It is focused that because of their effective principles they could be able to manage the severe prehistoric climate condition successfully and lived for a long span of life. The prehistoric Akkie population might have been completely extinct at one stage during expanding universe before new generation started living on Earth planet with different genetic structure. Authors consider that the Akkie population shall be considered as a seed and genetic link to earthly population (Ref. $[1,2,6,7])$. The Akkie populations shall be considered as genetically different populations and modern human shall be considered as genetically transformed populations. In the philosophy of modern management the key parameter transformation shall be translated as fundamental concept which shall mean restoring to perfectness or super management principles. In other words it shall be stipulated that restoring the human mindset tuned with prehistoric Akkie principles to reach perfectness (Ref. [2,4]).
\end{abstract}

Keywords: Akkie Code; Crop Circles; True Transformation; Strategy; Etymology of Word Manage; Manuscript; Philosophy of Theory; Philosophy of Victory; Bankruptcy; Logos, Amulet

\section{Objective of This Article}

The objective of this article is to focus that human ancestors are not apes lineage. The prehistoric human has more genetic value than apes and they were highly wise and great astronomers in controlling various planets in prehistoric time through most advanced management techniques and through most advanced scientific language in code form called as AKKIE CODE (also called as MARS CODE). They were capable of manag- 
ing were more climate change condition in prehistoric time and more immune to environment and, hence, they were living thousands of years and have a span of life. It is speculated by the author that the prehistoric population might be totally extinct at one stage and new generation on EARTH PLANET might have started by natural selection. The prehistoric Akkie population lived on MARS planet shall also be considered as ALIENS (Ref. [1,2, $6,7])$.

\section{Red Focus on Salient Parameter on the Objective of This Article}

The objective of this article having many complex hypothesis shall be considered to provide solution to many present day global level problem and prevailing mysteries as mentioned below:

1) Hypothetical solution to origin of prehistoric human.

2) Hypothetical solution to prevailing mysteries of about existence of so called STAR HUMAN, ALIEN (Ref. [1,8]).

3) Hypothetical solution for prevailing mysteries of existence of high level scientific language in prehistoric time.

In Greek mythology there was a belief about existence of star human, alien in the past. The formation of global level crop circles still considered as mysteries and the scientist could not find what is the reason for formation of crop circles.

In Rig vedha it is believed that prehistoric population (so called mu population) believed to have existed in the lost continent of LEMURIA. It is stipulated that the prehistoric population was so wise and done great wonders in prehistoric time and have been completely extinct during the course of expanding universe due to various change in abnormal climate condition (Ref. [1,9]).

From BIBLICAL case study it is understood that the prehistoric population were existing since ADAM and EVE origin and at one stage all the populations were ruined and new population started from NOAH origin (Ref. [6]).

In the resent MARS mission, the NASA's administration confirmed the existence of prehistoric life in MARS planet and cited evidence for having existence of CYDONIA city with high level super structure advanced civilization. They also confirmed that high level language in the form of CODE SYSTEM were in usage in prehistoric time (Ref. [1]).

It is hypothesized by the author that prehistoric human population was in existence with different genetic structure. They were very wise and experts in astronomy and they shall also be called as super scientists. Super scientist shall mean having super wisdom compared to modern scientist shall mean having moderate wisdom. From evolution theory the origin of life still under mys- teries. Millers experiment, primordial soup theory also confirmed the spontaneous origin of life is impossible with artificial lightning developed in laboratory. It hypothesized by the author that the origin of life may not be possible with artificial lightning but it can be possible with natural electro magnetic radiation consists of three fundamental neutrino particles photon, electron, proton. It is further hypothesized that prehistoric human shall be considered as origin of first life. The prehistoric human on origin had only three chromosome derived one each from photon, electron, proton and having different genetic structure and capable of FLYING. The prehistoric human shall be considered as much more senior even to mosquito, amoeba having six chromosome, twelve chromosome in the lineage of evolution (Ref. [2-5]).

The prehistoric population shall be called as akkie population. Akkie shall mean (in prehistoric Tamil phonetics) NEUTRINO RADIATION by which the human origin might have been spontaneously evolved from dark energy. It is focused by the author that the prehistoric population was not only great astronomers but also great mathematician, super manager and they were effectively controlling the various planetary motion, tackled various climate changing condition and lived for long span of life in prehistoric time (Ref. [1,2,4]).

The three tiny dots alphabet is in usage in many ancient languages such as Hebrew, Arab, Persian, Sanskrit and Tamil. It is hypothesized by the author that the three tiny dots alphabet shall be considered as advanced scientific language code used by prehistoric population while lived in MARS planet. The three tiny dots shall be considered as the relative position of SUN, EARTH, MOON in prehistoric time formulated by prehistoric human. Further the three tiny dots shall be considered as unique TRIPHTHONG alphabet having integral part of prehistoric three Tamil phonetics and pronounced as AKKIE. It is hypothesized by the author that the three tiny dots shall be called as advanced electromagnetic code (in quantum physics it shall be called as black box code) used by akkie population for controlling various planetary motion. It is focused that the codal language such as Morse code, Binary code, Mayan code might have been derived from the philosophy of prehistoric Akkie code (MARS Code) (Ref. [1,4,8-10]).

It is speculated by the author that the biblical ADAM and EVE population probably might have lived in MARS planet in prehistoric time and not on Earth planet. It is speculated that the Adam and Eve population might have been completely extinct at one stage due to various climatic condition and NOAH population might have started living on Earth planet with different genetic structure. It is speculated by the author that the Adam and Eve population might have had only three 
chromosome and NOAH population might have acquired 46 chromosome derived genetic link from three chromosome population during the course of lineage of evolution (Ref. $[1,2,6])$.

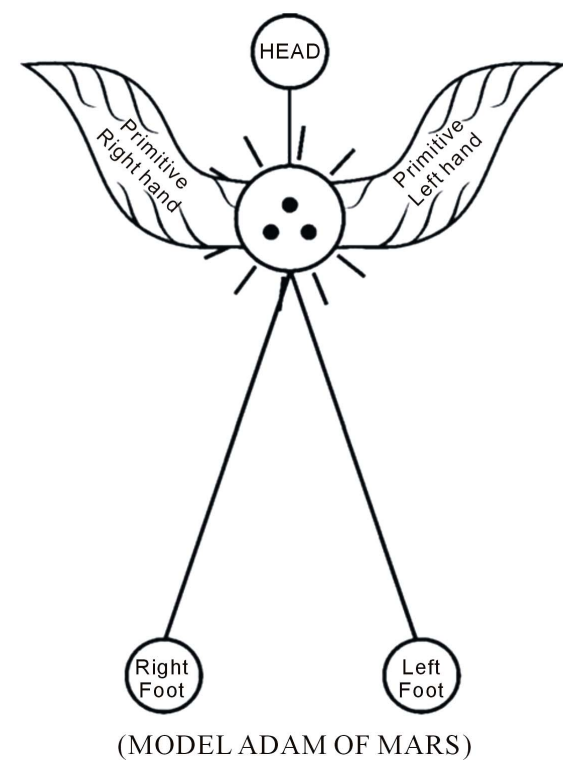

\section{Previous Publications}

This article titled as "Three principles of AKKIE MANAGEMENT" shall be considered as extended version of the previous articles published by the author with certain salient repetition cited for focus in this article. The philosophy of origin of life, prehistoric human usage of high level scientific language in prehistoric time were already published in the international journals as stipulated below:

1) The Super Scientist of Climate Control (IJSER, May issue, 2013).

2) Akkie Mars Code (IJSER, June issue, 2013).

3) Mars Trisomy Human (IJOART, June issue, 2013).

4) Mars Mathematics (IJERD, June issue, 2013).

5) The Mystery of Crop circle (IJOART, May issue, 2013).

6) Origin of First Language (IJIRD, June issue, 2013).

\section{Introduction}

In the competitive world different strategies are adopted to win the race. Tactics in Management shall be considered as the part of strategies. But ultimately only one can win! What is the secret of winning? It is focused that the element of commonsense shall be considered as most viable, vital, key area rather than Intelligence. It is the speculation of the author that a person have more commonsense can ultimately win the race and sustainable rather than a person having more intelligence and Tactics. In Akkie Principles of Management common sense and vision shall be considered as the right side of human Brain and intelligence and mission shall be considered as left side of human brain. Further it is focused that the Philosophy of System Management shall be considered as containing both Science and Art. Science shall be considered as INTELLIGENCE. Art shall be considered as COMMONSENSE. It is the speculation of the author that commonsense is more powerful than Intelligence. Further it is focused that in modern management the area vision, mission shall be considered closely associated with science and art. In system management manager, scientist shall be considered as two prime organs of any organization. Scientists shall be considered as left hand responsible for MISSION; Manager shall be considered as right hand responsible for VISION. The third element normally missing in modern management theory shall be considered as WISDOM responsible for intuition (Ref. $[1,2,6]$ ).

\section{Hypothesis}

1) Prehistoric human (Akkie Population) lived in MARS shall be considered as Super Managers. Super manager shall mean having super intuition rather than intelligence (Ref. [1-3]).

2) Akkie code shall be considered as the three most fundamental principles of prehistoric management (Ref. $[2,3])$.

3) Logos Amulets, Crop Circles, shall be considered as the Millions of sub-rules to the three fundamental Akkie Principles (Ref. $[1,2,8]$ ).

4) The Etymology of word Crop Circle might be derived from Prehistoric Tamil Phonetics KIRAKAM CHARAM (Ref. [1,2,11]).

5) The Etymology of word, Man, Manure, Manage, Management, Manuscript, might be derived from the prehistoric Tamil phonetics MAAN, MANAM, MANTRAM (Ref. [1,2,8,11]).

\section{Human the Complex Organization?! (Author's Concept)}

Normally an organization is considered as having complex structure and needs thousands Management Principles such as different KRA, KPI, which are further subdivided into various sub areas like leadership, managerial, vision, mission, capability, Attitude, Motivation, Profitability, Feasibility, acceptability, liability, thousands of Ratios, Balance Sheet, Cost analysis, Incentive, marketing, introduction of new products etc. (Ref. [1,12]).

Many occasions, organizations are restructured and upgraded with new designation aiming to improve the performance. But still goals are lagging? Is there any wrong in Modern Management theory (Ref. [2])? 
It is focused by the author that HUMAN himself shall be considered as the Complex organization. The different parameters shall be considered as below (Ref. [1,2]).

1) Brain

CEO (System organization,

Intuition).

2) Right hand

Functional Part (VISION).

3) Left hand

4) Right foot

5) Left foot

6) Blood

7) Society

8) Blood purity

9) Good Health

(Smile).
Structural Part (MISSION).

Codel rules (Specification).

Resources (Materials).

Law (policy).

Environment (Value).

Transformation (Mindset).

Degree of Transformation

MARS CODE) (Ref. $[1,2,6])$.

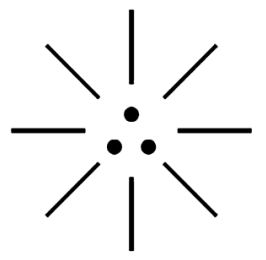

(Akkie Code)

(a)

\begin{tabular}{|c|c|}
\hline $\begin{array}{c}\text { Prehistoric "three dot" } \\
\text { formula related to Star }\end{array}$ & \multicolumn{1}{c|}{$\begin{array}{c}\text { Three dot alphabet usage in } \\
\text { global languages. }\end{array}$} \\
\hline$>$ Three dot is considered as \\
relative position" of Sun, \\
Earth, Moon in prehistoric \\
"Astronomy".
\end{tabular} $\begin{aligned} & \text { The three dot Prehistoric Tamil code } \\
& \text { is considered in usage in various } \\
& >\text { Sun } \\
& >\text { Earth }\end{aligned}$

(b)

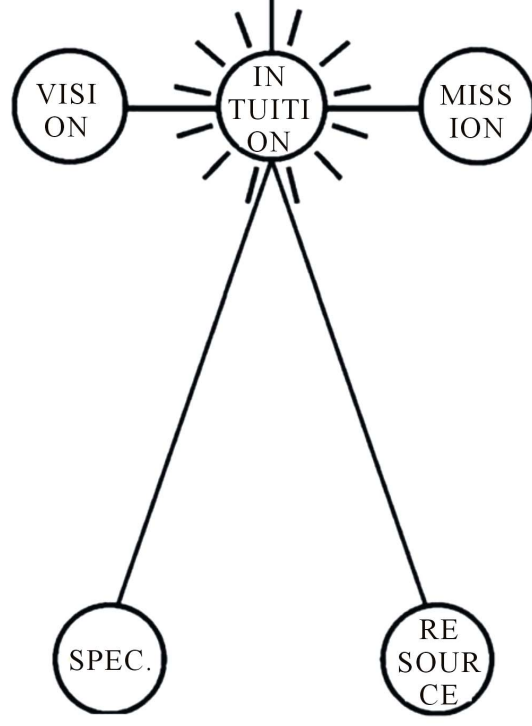

(Complex Organisation)

\section{Hypothetical Definitions}

\subsection{Philosophy of Akkie Code}

The Akkie code shall be considered as the Prehistoric Scientific language in code form with three tiny dots. It is focused that the three tiny dots shall be considered as the relative position of Sun, Earth, Moon. The Prehistoric human when lived in MARS shall be considered as SUPER MANAGERS have effectively managed the Movement of Various planets on its original position and overcome the severe climatic conditions faced due to misalignment of planets. Hence they could have lived for long span of life. In Modern Management various codal rules might have been derived from the fundamental philosophy of Prehistoric Akkie code (also called as

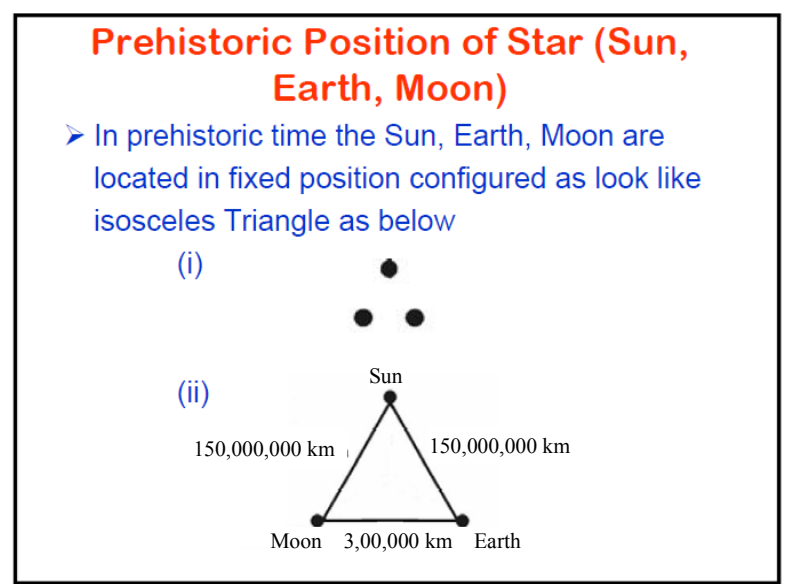

(c)

Modern Time Position of Star

In modern time the relative position of Sun, Earth, Moon is altered due to deviation. Moon going away from Sun. Which leads to asymmetry in isosceles Triangle

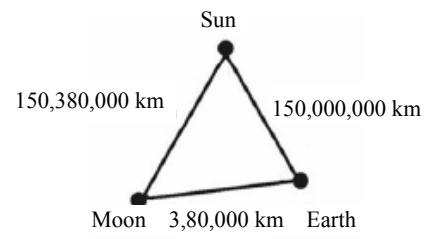

(d)

MA AKKIE shall mean megastar which shall be considered as the integral part of three Principal space 
objects SUN, EARTH, MOON. It is hypothesized that the Prehistoric population already formulated the relative position of Sin, Earth, Moon will three tiny dots called as Akkie code (Mars Code) (Ref. [1,2,6,8,11]).

In prehistoric Akkie principles the three dots shall be referred to three fundamental key responsibility area (KRA). The right dot shall be referred to vision responsible for functional part of system, the left dot shall be referred to mission responsible for structural part of system. The center dot shall be referred to intuition responsible for law part of system.

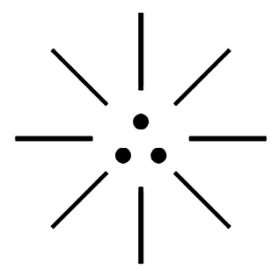

(VISION, MISSION, INTUITION)

In quantum physics the three dots shall be referred to three fundamental forces of Cosmo Universe. The right dot shall be referred to strong force (EMR), the left dot shall be referred to weak force (Neutrino Radiation). The center dot shall be referred to gravity force (dark flame radiation) (Ref. [1,2]).

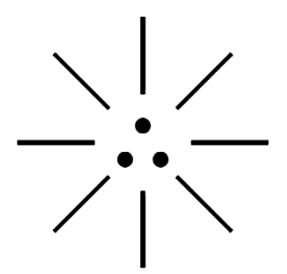

(STRONG, WEAK, GRAVITY)

In medical language the three dots shall be referred to fundamental parameters of Human Cell. The right dot shall be referred to DNA responsible for functional part, the left dot shall be referred to HORMONE responsible for structural part. The center dot shall be referred to RNA responsible for sequence part of human cell growth process. It is focused that in modern time cell division takes place with multiples of two, four. It is hypothesized that in prehistoric time the cell division might have taken place with multiples of three due to different environment condition (Ref. $[1,2,4,8]$ ).

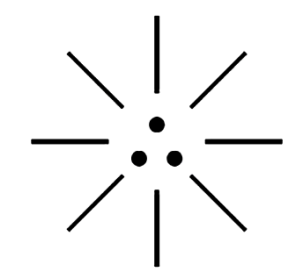

(DNA, HORMONE, RNA)

\subsection{Philosophy of Crop Circle}

It is focused that formation of crop circle in various parts of world are still considered as mystery and Modern Scientists could not ascertain what is the reason for formation of crop circles. It is focused that the various crop circle shall be considered as various electromagnetic discs (Software program) designed as specific strategy solution such as effective controlling the planetary motion, effectively altering the DNA structure of Natural plants for production of various Crops. It is focused that the philosophy of Aceae adopted for naming various types of plants adopted internationally might have been derived from the philosophy of Akkie code. The occurrence of various systematic formation of clouds in the atmosphere in different occasion shall also be considered as the effect of existing electromagnetic discs still left available in the MARS PLANET. The electromagnetic discs might have been operated with the Naturally available AETHER ENERGY in the space which consists of three fundamental neutrinos photon, Electron, Proton. The Aether energy shall also be alternatively called as black box energy. The etymology of word Aether might be derived from the prehistoric Tamil phonetics Akkie. Akkie shall mean Neutrino radiation (Ref. [1,2,4]).

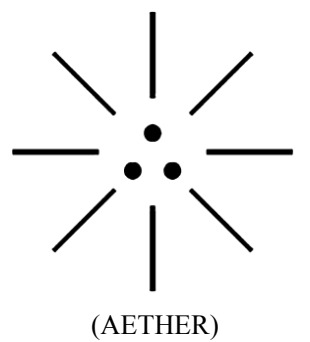

(a)

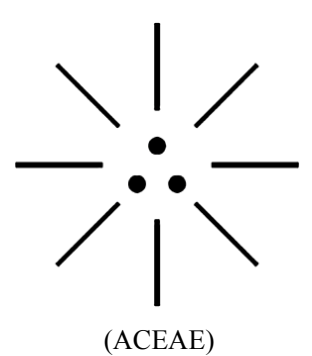

(b)

The right dot shall be considered as responsible for functional part of system universe, the left dot shall be considered as responsible for structural part of system universe, the centre dot shall be considered as sequence part (law) of system universe. Further the etymology of word Crop circle shall be considered as have derived from the Prehistoric Tamil phonetics KIRAKAM, CHARAM (Ref. [1,2,8,11]).

1) Kirakam shall mean Planet. 
2) Charam shall mean Order, Harmony.

3) Kiraka charam shall mean effective control of planets.

\subsection{Etymology of Word "Manage"}

The origin of Etymology word "Manage" is not clear. It is focused that the etymology of word Manage might be derived from prehistoric Tamil phonetics MAAN, MANAM, MANTRAM (Ref. [1,2,8,11]).

1) MAAN shall mean Expert.

2) MANAM shall mean Self esteem.

3) MANTRAM shall mean Society, People.

4) MANAGE shall mean lead the Society in expert way to protect Self Esteem.

Hypothetical New Definition for Management

Management shall be defined as an effort to devise instructional codal rules to protect the self esteem, environment of the society (or) to organize group of scattered elements properly aligned to achieve the desired goal. Manage shall also mean socialize and make peace (Ref. [2]).

-Author

\subsection{Etymology of Word Manuscript}

The origin of English word Manuscript is not clear the word manuscript shall mean a systematic, orderly written document which specifies the structural, functional, philosophy of a particular system. In short manuscript shall be considered as a set of codal rules in document form for specific objective of reaching the desired goal.

It is focused that the etymology of word manuscript might have been derived from the prehistoric tamil phonetics maan, manam, charam (Ref. $[1,2,8,11]$ ).

1) Mann shall mean Expert.

2) Charam shall mean sequence, order.

3) Mancham shall mean Heart.

Manuscript shall be considered as the written document emanated from the flow of energy from Heart (Mancham) (Ref. [2]).

-Author

\subsection{Philosophy of "Theory"}

It is focused that theory shall be considered as the set of scientific, philosophical, codal rules formulated in empirical form. The area of theory may be applied to many area such as scientific theory, Management theory, Economic theory, Anthropological theory, Language theory etc. It is focused that the philosophy of theory might be derived from the philosophy of "THIRI". Thiri shall mean Electromagnet radiation (EMR) which shall be considered as naturally influencing factor (IF) responsible for differences such a human skin colour, human hair colour, human eye iris colour, and responsible for various other interpersonal theory on human (Ref. $[1,2,11])$.

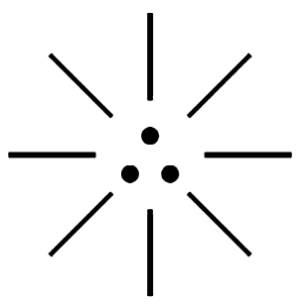

(THEORY)

It is focused that the philosophy of "strategy" might be derived from the philosophy of Thiri. The philosophy of strategy shall be considered as having three fundamental key area (shall be called in short as FKA) Vision, Mission, Intuition (Ref. [1,2,12]).

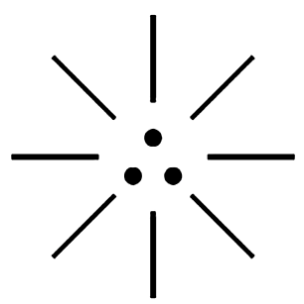

(STRATEGY)

The right dot shall be considered as responsible for functional part of system (Vision), left dot shall be considered as responsible for structural part of system (Mission), centre dot shall be considered responsible law, sequential flow of system process (Intution). In global level management theory the word strategy shall be considered as the overall system process from beginning to end to reach the desired objective.

Strategy shall be considered as a Management Master package classified under three fundamental key responsibility area (KRA). Tactics shall be considered as a sub area.

-Author

\subsection{Management is Science or Art?}

In Modern Management theory Management is considered as having influenced both scientific as well as nonscientific parameters. However thousands of theories are focused which ultimately leads to confusion and make the person to ultimately realize Management is Zero and not perfect. In short a person can finally conclude that common sense rules Intelligence shall be considered as 
absolute in Managing Sense (Ref. [1,2]).

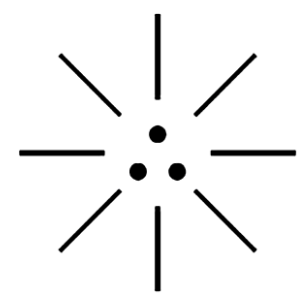

(Principle of Management)

The right dot shall be considered as ART (commonsense) responsible for functional part of system. Left dot SCIENCE (intelligence) shall be considered responsible for structural part of system, the centre dot shall be considered as responsible for law, sequence (wisdom) part of system (Ref. [1,2]).

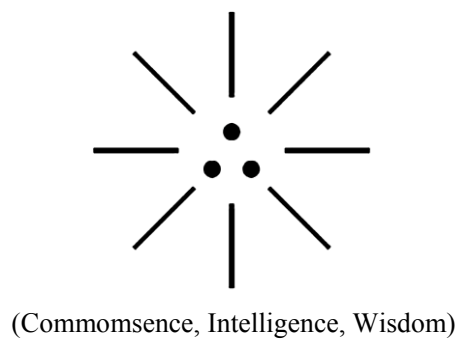

The three dot shall be considered as the three fundamental Principles of Management. Millions of sub dots within each main dot shall be considered as the subcodal rules of management (Ref. [1,2]).

\subsection{Philosophy of Bankruptcy}

The term bankrupt, bankruptcy in organizational language shall be referred to the inability to pay its obligation to the creditors and other third parties as per commitment.

The origin of word "Bankrupt" is believed to derived from Itallian origin "Banca rotta" means broken bench which focus breaking of money exchangers bench (or) Signification of Insolvency (Ref. [1,8]).

It is hypothesized that the etymology of word bankrupt might be derived from Prehistoric Tamil phonetics Panku and Rathu (Ref. [1,2,8,11]).

1) Panku shall mean share, society, people.

2) Rathu shall mean cancel, Break.

3) Panku Rathu shall mean Break of share (or) strength.

The right dot shall mean functional part of society, left dot shall mean Structural Part of Society, centre dot shall mean law part of society, for their smile and self esteem.

\subsection{Philosophy of Victory}

The philosophy of any Individual (or) organization shall be considered as governed by three fundamental Principles (Ref. [1,2,11,12]).

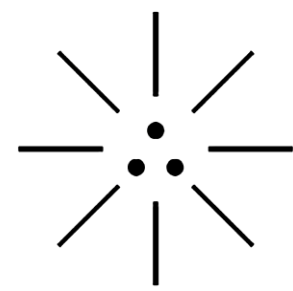

(VICTORY)

The right dot shall be considered as Attitude and motivation, left dot shall be considered as knowledge and skill, the centre dot shall considered as Intuition and environment health.

It is focused that the philosophy of victory might be derived from prehistoric Tamil phonetics VETRI. Vetri shall mean integral part of three fundamental principles of prehistoric Akkie Populations. Akkie principles shall be considered as EMPIRICAL rather philosophical (or) theory oriented.

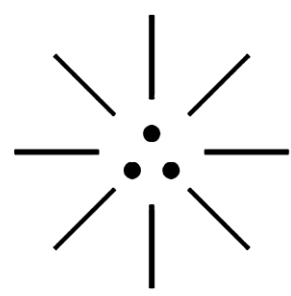

(Akkie Principle)

The right dot shall mean Dark mind responsible for functional part, left dot shall mean Dark flesh responsible for structure part, and centre dot shall mean Dark law responsible for Intuition part (Ref. [2]).

Further it shall be stipulated that any complex organization shall be formulated under three fundamental areas based on three fundamental Principles of Akkie management.

The above three dot shall be considered as three fundamental key Responsibility area (KRA). Each main dot shall be considered as having millions of sub dots which shall be considered as key Performance Indicators (KPI). The three KPA shall be considered a Functional Strategy, Structural Strategy, and Intuitional Strategy.

It is focused that any complex organizations, the Various Parameters Such as GPMS, FPMS, IPMS and various organizational resources, Incentive, motivation, attitude, skill managerial skill, Leadership quality, environmental condition, Society influence, Suitability, Feasibility, stability, Acceptability, Cost analysis, Price evaluation, Value gain Solvency, Bankruptcy can be accommodated with in three fundamental Management Principle of Prehistoric Akkie Populations lived in 
MARS Planet (Ref. [1,2]).

It is further focused that in Modern Management theory, the philosophy of management by objectives (MBO) focused by Peter Drucker and Various new Parameters such as 5 forces analysis, generic strategies, the value Chain, strategic groups, clusters, focused by Michael Porter shall also be considered as have derived from three fundamental Principles of Prehistoric Akkie Management.

\subsection{Philosophy of Logos}

The logo shall be referred to the system of symbol, graphic mark, emblem commonly used by commercial organization to aid and promote public recognition. The etymology of Greek word LOGOS, LOGIC, LOGISTICS might be derived from the word LOGO. The Greek word LOGOS, LOGISTICS, LOGY are referred to the meaning such as skilled in calculation, scientific study etc. It is hypothesized by the author that the prehistoric population when live in MARS is expert in logarithmic function of mathematics and other scientific studies. It is speculated that the prehistoric population might have adopted three tiny dots as natural logarithm mathematical symbol with base three. It is focused that in prehistoric time natural logarithm might mean adoption of logarithmic function with base 3 (Ref. [1,2,8]).

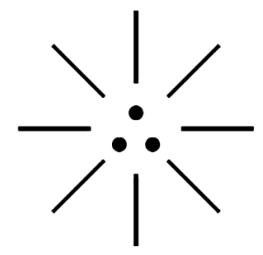

(Natural Logarithm Symbol with base three)

It is focused that the philosophy of mathematical constant e, pie might have been derived from the philosophy of prehistoric AKKIE CODE. It is focused that the philosophy of e, pie shall be considered as prehistoric mathematical parameter connected with relative position of SUN, EARTH, MOON in the space. In prehistoric time the Akkie population might have effectively controlled the logarithmic behavior of SUN, EARTH, MOON. Case study shows that astronomer have already confirmed that the MOON is moving away from its axis 3.8 centimeter per year. The modern scientist could not effectively control the planetary motion because of destroy of prehistoric effective scientific and managerial principles. It is speculated that the present day severe climatic change condition, global warming, frequent earth quake, unexpected flood, volcanic activity may be due to ASYMMETRY in relative position of SUN, EARTH, MOON compared to relative position in prehistoric time when it was SYMMETRY due to effective control of planetary motion by prehistoric population when lived in Mars planet. It is hypothesized that in modern mathematics the continual variation of universal mathematical constant $\mathbf{e}$, pie to millions of fractional endless digits may be due to continual asymmetry in relative position of SUN, EARTH, MOON.

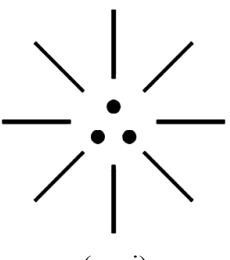

(e, pi)

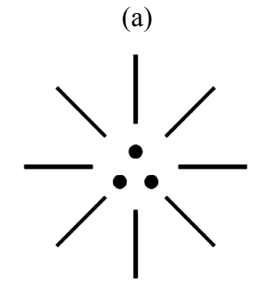

(SUN, EARTH, MOON)

(b)

\subsection{Philosophy of Amulet}

It is hypothesized that the prehistoric scientific techniques, strategies adopted shall be considered called as Amulet technology in modern time.

Case study shows that the word Amulet derived from Latin word Amuletum meaning an object that protects a person from evil spirit, evil doers. Further Amulet technology is considered as advanced graphical technology which enable manufacturer and product designer to evolve new techniques through GUI (Graphical User Interface). Further Amulet macro preprocessor allows to create macros which are used to make text substitution throughout HTML project. It is focused that the prehistoric population might have used Amulet marking which might have acted as ELECTROMAGNETIC SHIELD for protection against natural distortion like LIGHTNING.

It is speculated that the philosophy of Amulet technology might be derived from the philosophy of Akkie population called as Akkie technology. It is focused that the philosophy of Amulet might be derived from prehistoric Tamil phonetics Akkie, Ammu, Amulu (Ref. [1,2, $8,11])$.

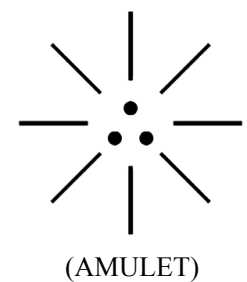

(AMULET) 
The right dot shall be considered as responsible for functional part, the left dot shall be considered as responsible for structural part, the center dot shall be considered as responsible for law, sequence part of Amulet technological system.

1) Akkie, Akkilen shall mean prehistoric human ancestor.

2) Ammu shall mean the mother supreme (Super Manager).

3) Amulet shall mean the super high technology.

4) Akkie Code shall mean the Principle of Prehistoric Management.

(Ref. [1,2,8,11]) -Author.

\subsection{The Philosophy of Alien?}

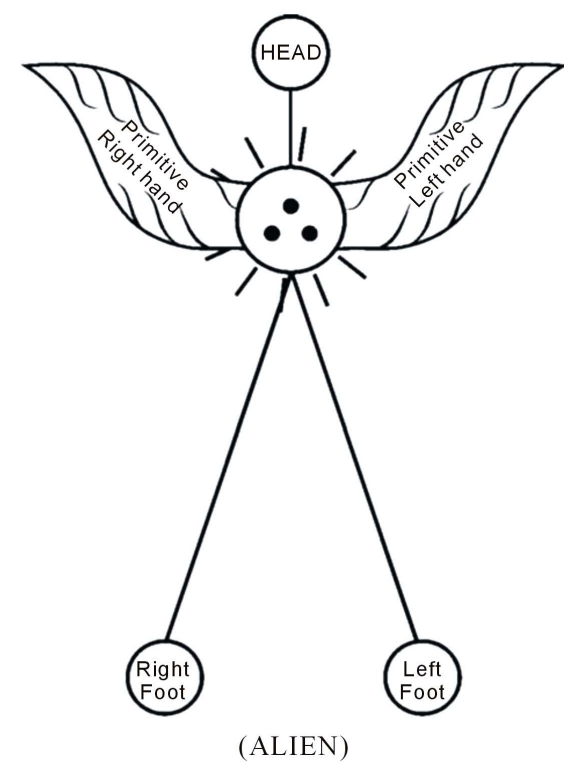

\section{Definition for Alien}

It is hypothesized that in prehistoric time the Akkie population might have been also called as ADAM, ALIEN, STAR HUMAN. Alien shall be defined as the prehistoric human evolved spontaneously due to impact of electromagnetic radiation from dark energy. The dark energy shall be considered as tissue consists of three fundamental neutrinos particles photon, electron, proton and Alien shall be considered as prehistoric human having three chromosome on origin derived each one from photon, electron, proton. The etymology of Alien might have been derived from the philosophy of Akkie human and prehistoric Tamil phonetic ANNIAN (Ref. [1,2,8,11]).

Genetic Value in Human Hand

It is focused that Modern human having two hands with proper fingers. It is hypothesized that the prehistoric populations while living in MARS might be having wing like hands in the Primitive level due to different chromosome level and genetic structure. Further the $\mathbf{4 8}$ Chromosome Apes are slightly deviated hands structure compared to Modern human. It is focused that 3 chromosome human, 46 chromosome humans are much senior to Apes who are having 48 chromosomes during the course of expanding universe (space and time) (Ref. $[1,2])$.

\subsection{Hypothetical Blood Diversity}

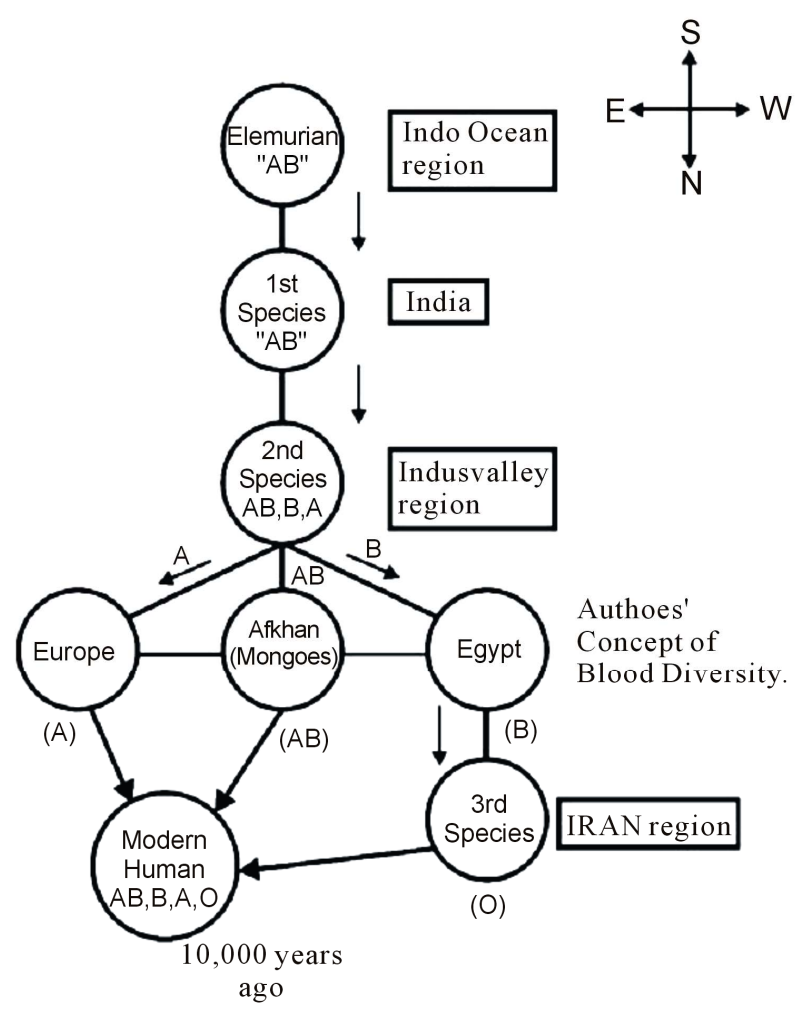

It is hypothesized by the author that from prehistoric time to modern time there may be three states of blood group might have been evolved due to impact of electromagnetic radiation. "O" type blood (universal donor) might be evolved during modern period (Ref. [1,2,8,11, 13]).

1) Stage i-AB type only (AKKIE POPULATION, ALIEN).

2) Stage ii- $\mathbf{A B}, \mathbf{A}, \mathbf{B}$ (DRAVIDIAN ORIGIN).

3) Stage iii-AB, A, B, O (ARYAN ORIGIN).

It is focused that in the lineage of evolution all the four type of blood might not have been evolved at one stage and might be evolved in phased manner in different stages. It is speculated that the origin of Dravidian population shall be considered much earlier to the origin of Aryan population.

The term ABORIGINAL in human anthropological science shall mean AB + ORIGINAL i.e. AB type blood 
shall be considered as evolved on origin. It is focused that the blood type of prehistoric human shall be considered as AB type (Universal Acceptor) (Ref. [1,2]).

\section{Management philosophy 2013 (Author's Concept)}

The author attempts to focus new management philosophy suitable to global level organization of different region.

Every living organism has its own management technique for survival and sustainability of life. The philosophy of management is required only for human and not for animals and other life organisms. Human has more genetic value than other organisms. Further human exists not for survival alone but for something more... Akkie principles shall be considered as base for overall SYSTEM MANAGEMENT.

In any organization a person having more commonsense shall be considered as ARTIST (LEADER) and a person having more intelligence shall be called as SCIENTIST (MANAGER) and a person having more intuition shall be called as PHILOSOPHER (CREATIONIST). The system management shall be considered as the integral part of artist, scientist, philosopher (Ref. $[1,2$, 12,14-16]).

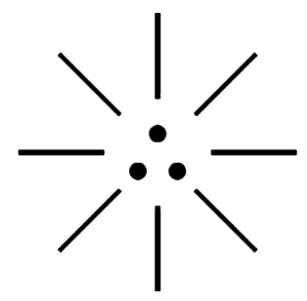

(System Management)

1) Right dot shall mean artist (VISION).

2) Left dot shall mean scientist (MISSION).

3) Center dot shall mean philosopher (CREATION).

The above three dots shall be considered as three fundamental key responsibility area (KRA) in system management in any global level organization. Each dot shall be considered as having millions of sub dots called as key performance indicators (KPI) which may be referred to every minute sub activity in the respective KRA. In other words every KPI shall be considered as specific software program to deal with specific problem of organization.

"Management principles are like medicines promoting reaction and change for good organizational, environmental health. The medicines may be Tamil medicine (Nattu Marunthu), Indian medicine, English medicine, French medicine, Chinese medicine... which suits the environment of electromagnetic radiation (EMR) of respective region. AKKIE (AMMU) principle shall be con- sidered as the MOTHER of global management principle. The philosophy of Morse Code, Mayan Code, Algorithm, Logo Gram, Amulet might have been derived from the philosophy of prehistoric AKKIE CODE" (Ref. [1,2,4]).

$$
\text { -Author. }
$$

\section{Conclusions}

In modern management theory even the most talented Manager would no doubt agree that "comprehensive analysis" is impossible for complex problems. Formulation and implementation of strategy must occur side by side rather than sequentially. It is stipulated that in the contemporary management, the assumption which are made in the absence of perfect knowledge will never be perfectly correct in achieving the desired goal. Further it is focused that the precise transformation process in every organization shall mean that it shall be exactly aligned with three fundamental principles of prehistoric Akkie principles (Ref. [1,12]).

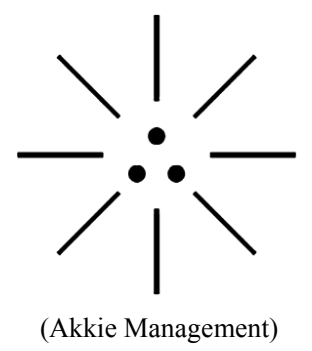

The right dot shall be considered as dark mind responsible for the functional part of the system. The left dot shall be considered as dark flesh responsible for structure part of the system. The centre dot shall be considered as dark law responsible for law, sequential part of the system. Many occasions when new strategy is formulated the stipulation of speed of transformation become absent. Every Individual of organization can access its own degree of transformation status (i.e. degree of darkness) in the process from top to bottom. More darkness in deed shall mean more strength. Further the restructuring is more likely to be successful when managers first understand the fundamental business/strategy problem that their company focus.

1) Conclusion on base language of management

The principles of management shall be considered as a tool required for the functional part of any organization. But language shall be considered as the base for framing documentation of any principles or theory. If so what was the first language? It is hypothesized that the first language might have been originated from prehistoric Akkie population lived on MARS (Ref. [1,2,9,17-19]).

The prehistoric Akkie language shall be classified under three stages of evolution: 
a) Child language.

b) Ezhem language.

c) Classic language.

It is focused that the Akkie population might have called parents as AMMU, AYYA in prehistoric time. In global level language whether Indian child, American child, African child, European child, Australian child, the first phonetic alphabet pronounced by any child shall be considered as AMM... AMM... AMM... This shall be called as child language. In the second stage the child shall pronounce as AMMU... AMMU... AMMU... This shall be called as Ezhem language. Ezhem language shall mean pronouncing a word in lengthy way i.e. AMM is pronounced as AMMU... AMULU... or AMMOO... Similarly RAM is pronounced as RAMU... RAMULU... RAMOO... In the third stage the word AMMU, AMULU is pronounced as AMMA. This phonetic AMMA shall be considered as a classic form of AMM... or AMMU.

It is focused that the philosophy of English word "AM" might be originated from prehistoric Tamil phonetic AMM or AMMU. "I am" shall mean parent or origin (Ref. $[1,2,8,11,20,21])$.

"I" stands for AYYA (FATHER).

"AM" stands for AMMU (MOTHER).

"I AM" stands for PARENT or ANCESTOR.

2) Conclusion on mathematical constant usage in management

It is focused that mathematics shall be considered as the law to formulate the behavior of the universe and its matters. The principle of mathematics shall be considered as the fundamental tool of any organization closely associated with ENVIRONMENT, NATURE. Conducive environment, nature is the important parameter for successful management of any organization.

In modern mathematics the three mathematical constants $\mathbf{e}$, pie, $\mathbf{i}$ are considered as prime parameters in formulating the behavior of nature and universe since prehistoric time. It is focused that the philosophy of the three fundamental mathematical constant might be derived from the philosophy of AKKIE CODE.

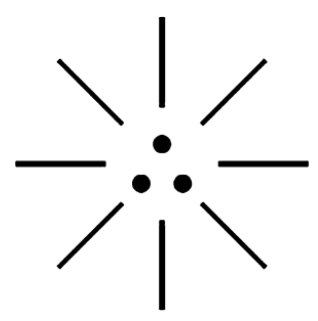

(e, pie, i)

The right dot (e) shall be considered as responsible for functional part of nature behavior, the left dot (pie) shall be considered as responsible for structural part of nature, the center dot (imaginary number i) shall be considered as responsible for law, sequence part of nature.

In prehistoric time the Akkie population has well managed the various planetary motion and kept nature and environment in balanced condition. Hence the mathematical constant might be highly stable in prehistoric time. In modern mathematics the mathematical constant $\mathbf{e}$, pie were observed as continuously varying to the level of thousands of fractional digits. It is hypothesized by the author that the continual variation of value of mathematical constant $\mathbf{e}$, pie may be due to asymmetry in relative position of SUN, EARTH, MOON. The hypothetical asymmetry among SUN, EARTH, MOON is indicated as below (Ref. [1,2,4]). (i)

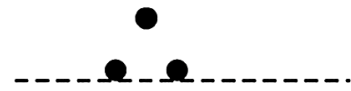

(ii)

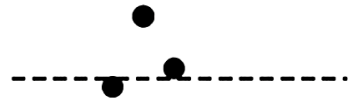

(iii)

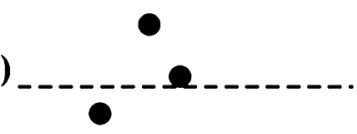

(iv)

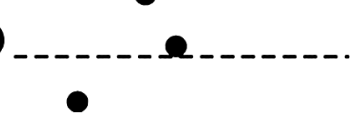

Prehistoric Period Position

\section{Ancient Period Position}

\section{Modern time Position}

By 3000 AD

It is speculated by the author that during modern period the modern scientist could not be effectively control and manage the planetary motion of the space. The present day climate change problem such as global warming, frequent earth quake, frequent cyclone, unexpected rain and flood, sudden forest fire, frequent volcanic activity may be due to asymmetry in relative position of SUN, EARTH, MOON (Ref. [1,2,4,22,23]).

Further it is speculated that the hypothetical variation in value of mathematical constant $e, p i e, i$ shall be indicated as below (Ref. [1,2]).

\begin{tabular}{ccccc}
\hline SI No & Value & $\begin{array}{c}\text { Prehistoric } \\
\text { Time }\end{array}$ & $\begin{array}{c}\text { Modern } \\
\text { Time }\end{array}$ & 3000AD \\
\hline 1 & $\mathrm{e}$ & 3.0 & 2.72 & 2.37 \\
2 & $\mathrm{pi}$ & 3.0 & 3.145 & 3.67 \\
3 & $\mathrm{i}$ & $\begin{array}{c}\text { Imaginary } \\
\text { number }\end{array}$ & $\begin{array}{c}\text { Imaginary } \\
\text { number }\end{array}$ & $\begin{array}{c}\text { Imaginary } \\
\text { number }\end{array}$ \\
\hline
\end{tabular}

\section{Case Study}

\subsection{Transformation Process in BSNL India}

After the birth of BSNL w.e.f. 1.10.2000 from parental 
unit P\&T, Dept. of telecommunications the BSNL planned its own strategies for transformation process for gaining its own value. The lineage of various stages shall be mentioned as below:

1) In 1997 TRAI was formulated to fix up various tariffs for various services

2) Up to 2007 the BSNL has adopted Vision to become the largest telecom service to provider in Asia and Set mission to provide world class stare of art technology telecom Services on demand at competitive Price and to provide world class telecom Structure in the area of operations and to contribute to the growt5h of country's economy.

3) In 2008,based on recommendation of international consultant M/S BCG SWOT analysis and project shikhar phase I was proposed for going ahed under phase I project various sub projects such as vijay, dosti udaan, sanchay, kuber and Smile were considered.

4) As the financial position was not improved and further to protect and to gain more value among competitive Environment in 2013 new vision and Mission have been focused. Under new vision the following three concepts were adopted.

a) Be the leading telecom Service Provider in India with global presence.

b) Create customer focused organization with excellence in Sales, Marketing and customer care.

c) Leverage technology to provide affordable and innovative poducts/services across customer segments including end-to-end converged services.

d) Based on formulation of new vision and mission it was decided to implement SHIKHAR phase II project with modified desigisnations among board of directors at corporate level and new KRA, KPI were identified under new strategy.

e) It is hoped by the experts of management that the transformation shall be true and effective in the years to come. They also focus that it requires a frame of mind set that admits of no boundry between means and ends (Ref. [1,12]).

\subsection{Transformation Process in AIR INDIA, India}

Air India the country's third largest airline by Market share recently announced its turnaround strategy due for completion by 2014. The company will aim to achieve a positive balance sheet by 2014-2015. The decision was approved following a meeting of the board of directors and employees with company's managements (Ref. [1]).

\subsection{Transformation Process in Global Level Organization}

10.3.1. General Motors

It is one of the biggest car manufacturing company of the world, with operation in more than 157 countries, 209,000 employees. In spite of various strategies the company eventually experienced a drastic decline in car sales and was lead to bankrupt in 2009. After receiving good financial aid from Government it came back on track with horror of bankrupts behind it (Ref. [1]).

\subsubsection{World Com Inc}

This is once the largest US based Telecommunication company went bankrupt in 2002 after its wrong expenses in spite of various strategies. It had more than 20 million customers and 80,000 employees. At the time of bankruptcy it was considered as one of the largest and vary famous companies in USA (Ref. [1]).

\subsubsection{Delta Airlines}

There was a time Delta Airlines was among the best and most profitable airlines in America. Due to rising of fuel prices and stiff competition from low cost airlines, it was proved fatal to airlines and become bankrupt in 2005 . But the scene was soon swapped in 2009 and the airlines again made comeback (Ref. [1]).

\section{Special Thanks}

Most of the data collected and new concepts presented in this article are based on case study from internet website through Google search. Author considers Google search mechanism as GOD or SUPER NATURE acting as a mediator to derive wisdom and intelligence from the global web link. Further heart felt thanks also extended to WIKIPEDIA, NASA'S administration for providing valuable information about prehistoric DARK CONTINENT EZHEM (INDO) (so called MARS RED PLANET) and in modern time and dedicated assistance extended by my office team. The prehistoric dark continent MARS planet might have become RED PLANET during the course of the expanding universe (space and time) (Ref. [1,2]).

\section{REFERENCES}

[1] "Intensive Internet "e-Book" Study through Google Search and Wikipedia," 2013.

[2] M. Arulmani, "3G Akkanna Man," Annai Publications, Cholapuram, 2011.

[3] M. Arulmani and V. R. Hemalatha, "Tamil the Law of Universe," Annai Publications, Cholapuram, 2012

[4] H. Koontz and H. Weihriah, "Essentials of Management," Tata McGraw-Hill Publications, New York, 2005.

[5] M. Arulmani and V. R. Hemalatha, "First Music and First Music Alphabet," Annai Publications, Cholapuram, 2012.

[6] King James Version, "Holy Bible," 2004.

[7] S. A. Perumal, "Human Evolution History," 2009. 
[8] "English Dictionary," Oxford Publications, Oxford, 2012.

[9] S. Devaneyapavanar, "Tamil First Mother Language," Chennai, 2009.

[10] Tamilannal, "Tholkoppiar," Chennai, 2007.

[11] "Tamil to English Dictionary," Suravin Publication, Chennai, 2009.

[12] “Text Material for E5 to E6 Upgradaton," BSNL Publication, New Delhi, 2012.

[13] A. Nakkiran, "Dravidian Mother," Chennai, 2007.

[14] M. Karunanidhi, "Thirukkural Translation," 2010.

[15] "Manorama Tell Me Why Periodicals," M. M. Publication Ltd., Kottayam, 2009.
[16] V. R. Hemalatha, "A Global Level Peace Tourism to Veilankanni," Annai Publications, Cholapuram, 2007.

[17] G. Pillai, "Sri Lankan Tamil History," 2004.

[18] K. K. Pillai, "South Indian History," 2006.

[19] M. Varadharajan, "Language History," Chennai, 2009.

[20] Y. S. Yagoo, "Western Sun,” 2008.

[21] G. Chettiar, "Adi Dravidian Origin History," 2004.

[22] M. Arulmani and V. R. Hemalatha, "Ezhem Nadu My Dream," 2 Parts, Annai Publications, Cholapuram, 2010.

[23] M. Arulmani and V.R. Hemalatha, "The Super Scientist of Climate Control," Annai Publications, Cholapuram, 2013, pp. 1-30. 